Kenneth D. Belanger · Aaron J. Wyman

Michelle N. Sudol · Sneh L. Singla-Pareek

Ralph S. Quatrano

\title{
A signal peptide secretion screen in Fucus distichus embryos reveals expression of glucanase, EGF domain-containing, and LRR receptor kinase-like polypeptides during asymmetric cell growth
}

Received: 25 March 2003/ Accepted: 28 April 2003/Published online: 27 June 2003

(C) Springer-Verlag 2003

\begin{abstract}
Zygotes of the brown alga Fucus distichus (L.) Powell develop polarity prior to the first embryonic cell division and retain a pattern of asymmetric growth during early embryogenesis. In order to identify $F$. distichus polypeptides secreted during asymmetric cell growth, we used a functional assay in Saccharomyces cerevisiae to screen a cDNA library generated from asymmetrically growing Fucus embryos for sequences encoding polypeptides that function as signal peptides for secretion. We isolated and sequenced 222 plasmids containing Fucus cDNAs encoding signal peptide activity. The cDNA inserts from these plasmids were translated in silico into 244
\end{abstract}

K. D. Belanger $(\bowtie) \cdot$ A. J. Wyman

S. L. Singla-Pareek · R. S. Quatrano

Department of Biology,

University of North Carolina - Chapel Hill,

Chapel Hill, NC 27759, USA

E-mail: kbelanger@mail.colgate.edu

Fax: + 1-315-2287997

K. D. Belanger

Department of Biology, Colgate University,

Hamilton, NY 13346, USA

K. D. Belanger · M. N. Sudol

Department of Biology, University of Scranton, Scranton,

PA 18510, USA

Present address: K. D. Belanger

Department of Biology, Colgate University,

Hamilton, NY 13346, USA

Present address: A. J. Wyman

Department of Molecular, Cellular, and Developmental Biology, University of Michigan, Ann Arbor, MI 48109, USA

Present address: M. N. Sudol

Philadelphia College of Osteopathic Medicine,

Philadelphia, PA 19131, USA

Present address: S. L. Singla-Pareek

International Center for Genetic Engineering \& Biotechnology,

New Delhi, India

Present address: R. S. Quatrano

Department of Biology, Washington University,

St. Louis, MO 63130, USA potential polypeptide sequences, 169 of which are predicted to contain signal peptides. BlastP analysis of the Fucus sequences revealed similarity between many Fucus proteins and cell surface proteins that function in development in other eukaryotes, including epidermal growth factor (EGF)-like repeat-containing proteins, plant leucine-rich repeat (LRR)-receptor kinases, and algal $\beta$-1, 3exoglucanase. However, most of the isolated Fucus polypeptides lack similarity to known proteins. The isolation of cDNAs encoding secreted Fucus proteins provides an important step toward characterizing cell surface proteins important for asymmetric organization and growth in fucoid embryos.

Keywords EGF-like repeats · Fucus - Glucanase · Polarity $\cdot$ Secretion $\cdot$ Signal peptide

Abbreviations ECM: extracellular matrix - EGF: epidermal growth factor - ER: endoplasmic reticulum $\cdot$ LRR: leucine-rich repeat SST: signal sequence trap - WAK: wall-associated kinase

\section{Introduction}

Polar cells exhibit different morphological and/or molecular characteristics at opposing ends, with these distinct ends aligned along an axis of symmetry (Grebe et al. 2001). Polar organization allows distinct regions - and distinct surfaces - of a single cell to have markedly different activities. Cell surface molecules play important roles in generating and retaining cellular polarity, including sensing the extracellular environment, adhering cells to adjacent surfaces, and linking the internal contents of the cell physically to the extracellular environment (Quatrano 1997; Doe and Bowerman 2001). Because secreted polypeptides are involved in cell signaling and structural functions in polar cells, the identification of novel cell-surface proteins is important for understanding 
the molecular basis of the generation and maintenance of cellular asymmetry. Surface molecules fulfilling these functions serve important roles in the generation and maintenance of polarity in many diverse cell types, including prokaryotes, fungi, protists, metazoans, and plants (reviewed in Drubin and Nelson 1996; Cove 2000).

The fucoid brown algae, including Fucus and Pelvetia species, provide model organisms for studying the role of cell surface molecules in the generation of cell polarity and subsequent asymmetric cell growth. Fucoid algae exhibit an early developmental pattern in which zygotes generated from symmetric eggs undergo the formation - and eventual fixation - of a polar axis in response to environmental cues, including unilateral light (reviewed in Quatrano 1997; Brownlee et al. 2001). Fucoid zygotes develop cortical and cell surface asymmetries as polar development progresses. While the initial secretion of extracellular material is symmetric (Quatrano 1982; Hable and Kropf 1998), a polar axis forms within a few hours of fertilization (Hable and Kropf 2000). Associated with the formation of this polar axis is an asymmetric targeting of molecules, creating a localized accumulation of specific polypeptides (Wagner et al. 1992; Shaw and Quatrano 1996; Pu et al. 2000) and carbohydrates (Quatrano and Crayton 1973; Novotny and Forman 1974; Brawley and Quatrano 1979; Hable and Kropf 1998) at the cell surface prior to the visible morphological changes associated with asymmetric cell growth (Quatrano and Shaw 1997). The polarized secretion and deposition of these cell surface molecules is essential for fixation of the embryonic axis and for subsequent asymmetric growth (reviewed in Belanger and Quatrano 2000a; Brownlee et al. 2001). Thus, determining the identity of polypeptides localized to the surface of polarized embryos is critically important to our understanding of the mechanisms of axis formation and asymmetric cell growth.

The vast majority of proteins expressed at the cell surface of eukaryotic cells are targeted to the plasma membrane via vesicle-mediated secretion (reviewed in Vitale and Denecke 1999). The cotranslational translocation of a secreted protein into the endoplasmic reticulum (ER) is dependent upon the presence of an endogenous signal peptide within the secreted polypeptide (Johnson and van Waes 1999). This signal peptide is a degenerate, highly variable stretch of 15-50 amino acids containing a hydrophobic $\alpha$-helical core of $6-15$ residues which is flanked at both the amino and carboxyl ends by polar residues (Nielsen et al. 1997; Martoglio and Dobberstein 1998). After translocation into the ER, proteins are secreted to the cell surface through the ER to Golgi to exocytotic vesicle transport pathway, unless they contain an additional sorting signal targeting them to an intracellular compartment within the endomembrane system (Vitale and Denecke 1999).

Despite evidence linking cell surface molecules to axis formation and asymmetric cell growth in fucoid embryos, specific secreted molecules that regulate or promote polar orientation and/or growth have yet to be identified. Mutations in secreted proteins from the yeast Saccharomyces cerevisiae have frequently been used to examine the molecular mechanisms of secretion in eukaryotes (Kaiser et al. 1987; Ngsee et al. 1989). In an effort to identify cell surface proteins that are potentially important for development of asymmetry and subsequent asymmetric cell growth in fucoid embryos, we have used a signal sequence trap (SST; Klein et al. 1996; Jacobs et al. 1997) to screen a Fucus distichus cDNA library for polypeptides that function as signal peptides in yeast. We isolated 222 cDNA sequences, of which 169 are predicted to encode a polypeptide containing an amino-terminal signal peptide. BlastP analysis (Altschul et al. 1990) revealed that a significant fraction of these Fucus polypeptides exhibits regions of similarity to cell surface proteins that were previously identified in other organisms, including leucine-rich repeat (LRR) receptor-like kinases, metazoan cadherin-like proteins, and $\beta$ 1,3-exoglucanase. However, most of the polypeptides identified in this screen appear to be novel. We discuss the potential roles in asymmetric growth of several putative proteins isolated in this screen.

\section{Materials and methods}

Construction of Fucus libraries and SST control plasmids

A synchronous population of Fucus distichus (L.) Powell embryos was obtained as previously described (Belanger and Quatrano 2000b). mRNA was isolated from asymmetrically growing 18 -h embryos by hexadecyltrimethylammonium bromide (CTAB) extraction and precipitated using $\mathrm{LiCl}$ (Apt et al. 1995). A cDNA library was generated using the 2 ZAPII random-prime library kit (Stratagene, La Jolla, CA, USA). Plasmid DNA was excised from the $\lambda$ ZAPII phage using standard protocols, and Fucus cDNA inserts were isolated from the phagemids using restriction endonucleases EcoRI and XhoI. The cDNA inserts were purified by agarose gel electrophoresis and ligated directionally into the EcoRI and XhoI sites of the SST vector pSUC2T7M13ORI (Jacobs et al. 1997). Electrocompetent DH10B Escherichia coli were transformed with the library and resulting transformants utilized without amplification for plasmid DNA isolation.

The Wak2-79::SST fusion was constructed by digesting Wak2cDNA (He et al. 1999) with EcoRI and XcmI and inserting the resulting fragment encoding the amino-terminal 79 amino acids of Wak2 into the SacII site of the pSUC2T7M13ORI SST vector by blunt end ligation. Wak2-222::SST was synthesized by digesting Wak2-cDNA with EcoRI and StuI and ligating the resulting fragment into EcoRI and $S c a$ I sites of the SST vector. The Act2$52::$ SST fusion was generated by digesting Act 2 cDNA (An et al. 1996) with HindIII and $N s i \mathrm{I}$ and cloning the excised Act 2 fragment into the SST vector at EcoRI and StuI sites. Act2-359 was cloned similarly, by excising Act2 using HindIII and StyI and inserting the resulting fragment into SST vector EcoRI and StuI sites. DNA sequencing of each plasmid was performed to confirm in-frame fusion between the Wak2 or Act2 insert and the $S U C 2$ invertase gene located on the SST plasmid.

Yeast transformation and selection

Library plasmids were transformed into yeast strain YTK12 (suc2 $\Delta 9$ trp1s ade2-101 ura3-52; Jacobs et al. 1997) by lithium acetate transformation (Ito et. al. 1983). Forty-eight thousand $\operatorname{Trp}^{+}$transformants were obtained by selection on complete 
minimal media lacking tryptophan (Ausubel et al. 1995) and containing $0.1 \%$ dextrose and $2 \%$ sucrose. Transformants were incubated at $30{ }^{\circ} \mathrm{C}$ for $2-3$ days, and then replicated onto YEP media containing 2\% raffinose (YP-Raf) as the sole carbon source. After incubation at $30{ }^{\circ} \mathrm{C}$ for 3 days, viable colonies were restreaked to YP-Raf and grown at $30^{\circ} \mathrm{C}$ for $4-6$ days. Plasmids were isolated from viable colonies by glass bead lysis, transformed into DH10B E. coli, and isolated by miniprep procedure. Plasmids were retransformed into YTK12, and transformants were treated as described for the screen above. Two hundred and sixty nine plasmids that conferred growth on YTK12 yeast on sucrose and on raffinose were retained for sequencing.

\section{Plasmid sequencing and analysis}

The plasmids were sent to the University of North Carolina-Chapel Hill (Chapel Hill, NC) Automated DNA Sequencing Facility for Taq FS Dye Terminator sequencing of the Fucus cDNA inserts using the primer 5'-CTG CAC AAT ATT TCA AGC TAT ACC AAG $\mathrm{C}-3^{\prime}$. The 222 resulting sequences were analyzed visually using Abi-Prism EditView (Perkin Elmer) and cDNA inserts translated in silico using ExPasy translation tool (Appel et al. 1994). Polypeptide sequences were compared with sequences in Genbank using BlastP (Altschul et al. 1990) and examined for signal peptides using SignalP (Nielsen et al. 1997) and TargetP (Emanuelsson et al. 1999).

\section{Results}

The SST screen we have employed to identify secreted proteins in Fucus distichus utilizes a mutant invertase lacking a signal peptide to identify exogenous sequences that can target the mutant enzyme to the cell surface (Jacobs et al. 1997; see Fig. 1). While this signal peptide selection screen had previously been used to identify signal peptides from human and rat libraries (Klein et al. 1996; Jacobs et al. 1997) and from plants (Goo et al. 1999), the ability of this system to recognize signal peptides from brown algae had not yet been determined. In order to initially confirm the ability a plant signal

a.

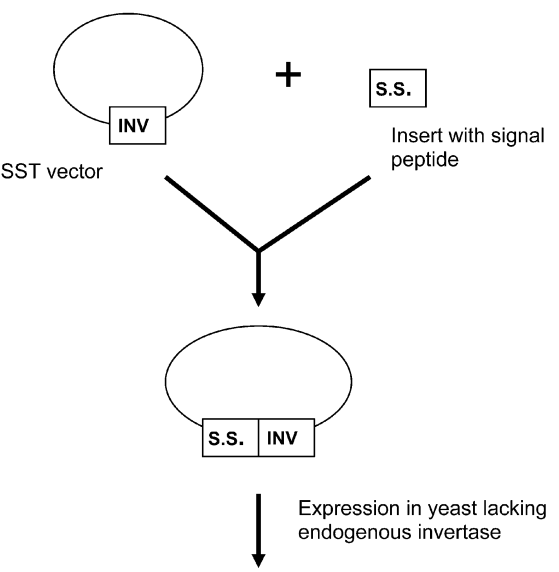

SS::INV

Secreted fusion protein peptide to mediate detectable secretion from yeast using the mutant invertase vector in the SST system, we cloned sequences encoding the amino-terminal region of the secreted plant wall-associated kinase WAK2 (He et al. 1999) in-frame with the mutant invertase on an SST vector (Jacobs et al. 1997). We then assayed yeast expressing the WAK2::invertase fusion for growth on sucrose (Fig. 2). WAK2::invertase fusions containing the amino-terminal 79 and 222 amino acids of WAK2 allow a yeast strain otherwise lacking invertase to grow on sucrose, indicating that these WAK2 sequences do function as signal peptides in yeast and that these plant sequences can generate a positive result in this assay. Fusions expressing the first 52 or 359 amino acids of Arabidopsis actin, which lacks a signal peptide, do not confer growth on sucrose when fused to invertase. These data confirm that signal peptides from vascular plants can function in the SST selection. Fucus proteins containing signal peptides had not been previously identified, and thus could not be used as controls prior to initiating our screen for secreted Fucus polypeptides.

We utilized the SST selection to identify secreted proteins that may play a role in polar axis formation and asymmetric cell growth during early fucoid development. We generated a cDNA library using mRNA isolated from a synchronous population of Fucus embryos

Fig. 1a, b Use of the signal sequence trap (SST; Jacobs et al. 1997) to identify eukaryotic signal peptides. a Cloning of a nucleotide sequence encoding a signal peptide in-frame with an invertase mutant lacking its endogenous signal peptide generates a signal peptide::invertase $(S S: \because I N V)$ fusion. If the signal sequence is functional, the fusion protein is secreted when expressed in yeast. The resulting extracellular invertase activity confers viability on yeast cells cultured on media containing a disaccharide carbon source such as sucrose. b Expression of a fusion protein lacking a signal peptide $(X: \because I N V)$ precludes invertase secretion. Yeast cells failing to secrete invertase fail to grow on sucrose

b.

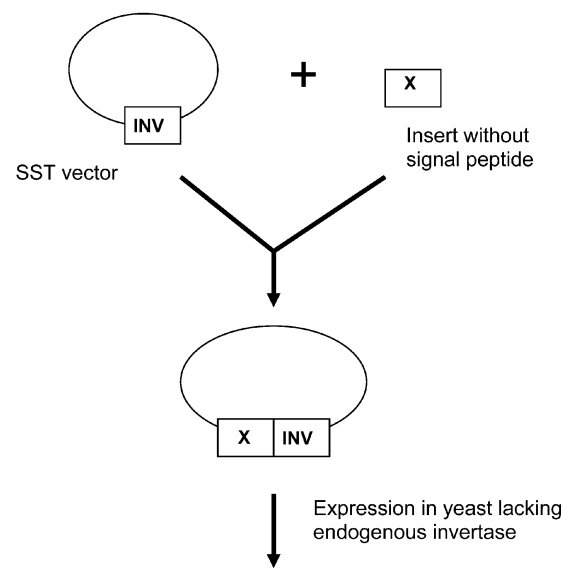

X::INV Fusion protein not secreted 
a.

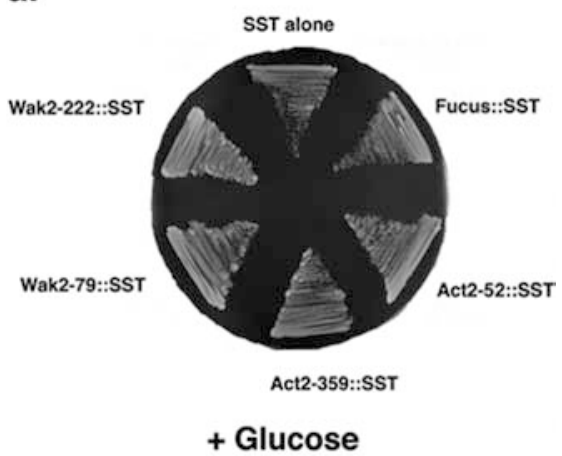

b.

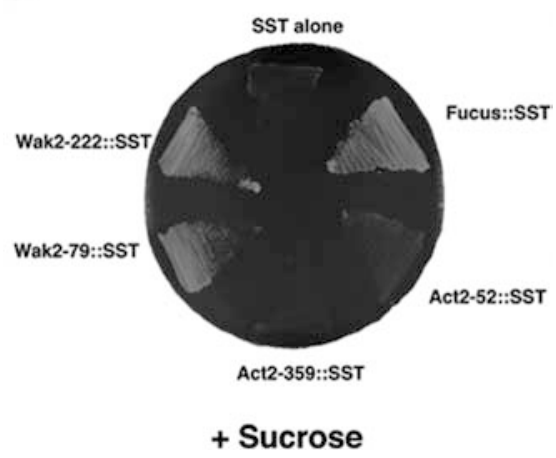

Fig. 2a, b The signal sequence trap can be used to identify secreted polypeptides from Arabidopsis thaliana and Fucus distichus. SST vectors expressing fusions of yeast invertase with the aminoterminal 79 amino acid residues (Wak2-79::SST) and 222 residues (Wak2-222::SST) of the secreted Arabidopsis Wak2 protein are viable on both glucose (a) and sucrose (b). Growth on sucrose requires extracellular invertase activity, confirming that Wak2 contains a signal peptide. Fusions of the amino-terminus of Arabidopsis actin Act2 (Act2-52::SST, Act2-359::SST) are not viable on sucrose, confirming the absence of a signal peptide in actin and the selectivity of the SST screen. A Fucus distichus cDNA insert fused to invertase as an isolate from the SST screen confers growth on sucrose (Fucus::SST), while the empty SST vector lacking an insert does not (SST alone)

$18 \mathrm{~h}$ after fertilization. At this developmental stage the two-celled embryos are undergoing rapid asymmetric growth at the presumptive rhizoid tip (Quatrano 1997) and should be expressing genes encoding proteins important for polar growth. In order to identify which of these genes encode signal peptides, we subcloned this cDNA library upstream of the invertase gene in the SST plasmid, and assayed for those Fucus sequences that could target invertase for secretion. In order to identify the polypeptides encoded by the secretion-positive Fucus clones, we isolated and sequenced each of the positive plasmids and translated the resulting sequence in silico. We were able to obtain readable sequence containing at least one detectable open reading frame from 222 plasmids. For some plasmids, the cDNA fragment encoded more than one open reading frame beginning with a methionine; thus, we examined more than one putative polypeptide sequence from some cDNAs. This analysis generated 244 different polypeptide sequences, which were then further characterized.
While the screen was designed to isolate polypeptides containing signal peptides, we could not easily confirm which of our polypeptides harbored a signal peptide. Due to the degenerate nature of signal peptides, a true signal peptide consensus sequence does not exist. However, several algorithms have been independently developed to predict the presence of a signal sequence in a novel polypeptide based on similarities in patterns of hydrophobicity, charge, polarity, and amino acid sequence among members of a large data set of confirmed signal peptide sequences (von Heijne 1986; Nakai and Kanehisa 1992; Nielsen et al. 1997). We utilized the SignalP signal sequence prediction program (Nielsen et al. 1997) to examine each Fucus polypeptide for a potential amino-terminal signal peptide. Of the 244 putative polypeptides (Tables 1,2) potentially encoded by Fucus inserts isolated from the SST screen, $169(69.3 \%)$ were predicted by SignalP to have an amino-terminal signal peptide (Table 1). If we take into account the inclusion in our analysis of multiple reading frames from some cDNA clones, the percent of isolated cDNAs encoding at least one signal peptide increases to $76.1 \%$ (169 of 222). Thirty-five different sequences were isolated more than one time (Table 3), and 30 of those 35 are predicted by SignalP to contain an amino-terminal signal peptide. Importantly, we have isolated 87 unique cDNAs that are expressed during asymmetric embryonic growth in Fucus embryos and encode a predicted signal peptide for targeting to the secretory pathway.

In order to gain potential insights into the function of the polypeptides encoded by these cDNAs, we performed a BlastP homology search (Altschul et al. 1990) on each predicted amino acid sequence against the GenBank sequence database (Tables 1,2). The BlastP results revealed similarity between a significant portion of the Fucus sequences and previously identified proteins entered into GenBank. Importantly, several Fucus polypeptides exhibit conserved sequences with metazoan and plant proteins with well-characterized roles in polarized cell growth. Three Fucus polypeptides (FucusSST036, 139, and 172) show similarity to epidermal growth factor (EGF)-like repeat-containing proteins from metazoans (Fig. 3a), while three others (FucusSST052, 067, and 102) exhibit similarity to leucine-rich repeat (LRR) receptor-like kinases from higher plants (Fig. 3b). In both cases, the similarity is confined to a defined region of the Fucus polypeptide. Six Fucus polypeptides exhibit a high degree of similarity to $\beta-1,3-$ exoglucanase from Neurospora crassa and other fungi (Fig. 3c). LRR receptor kinases, proteins containing EGF-like repeats, and proteins regulating glucan synthesis perform essential functions in mediating asymmetric growth and development in a broad range of organisms (see Discussion). BlastP also revealed similarity between Fucus sequences and calmodulin, a calmodulin-like protein, and a Rac-GTPase, all of which have also been proposed to play a role in polarized cell growth in other organisms (see Tables 1 and 2). 


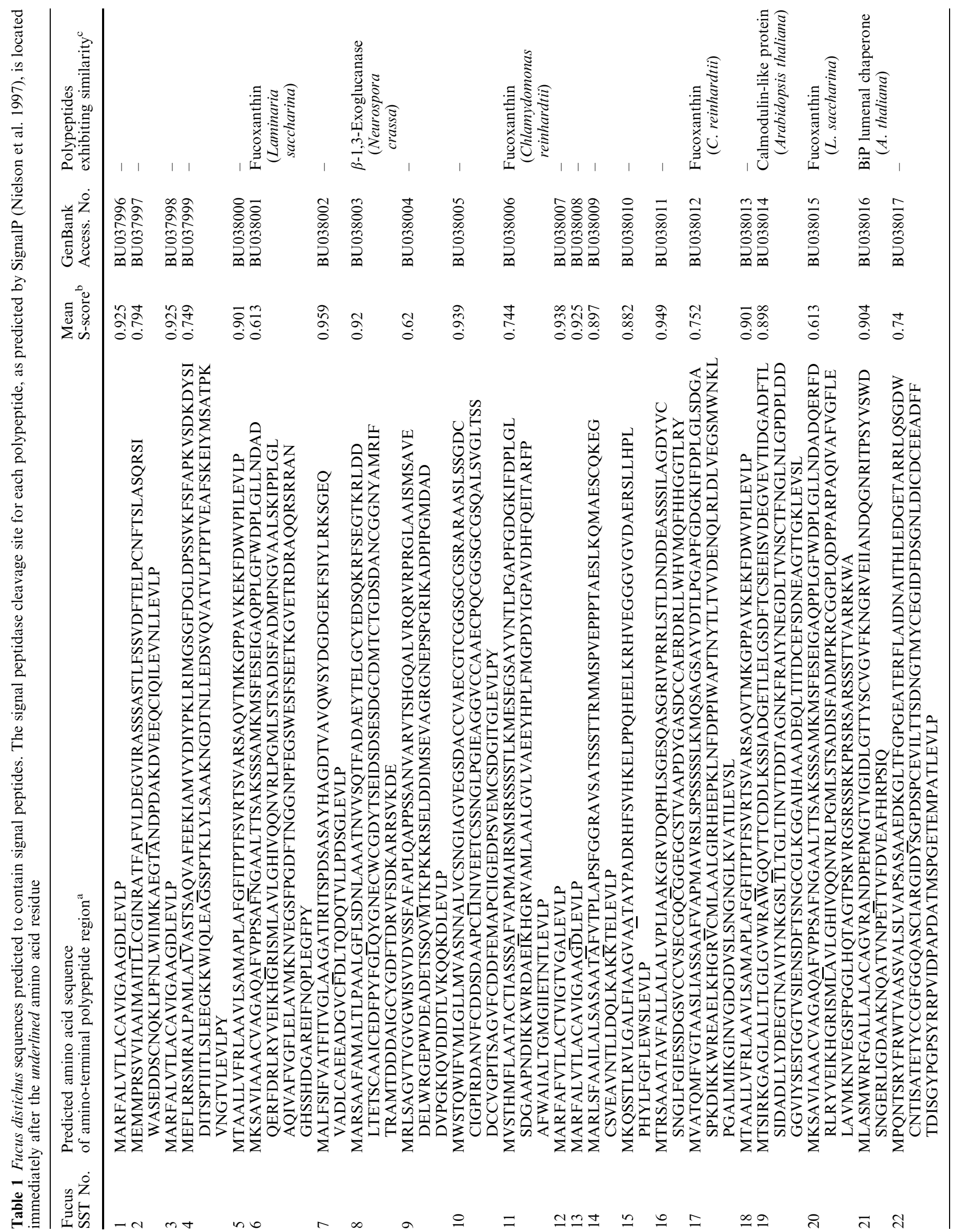




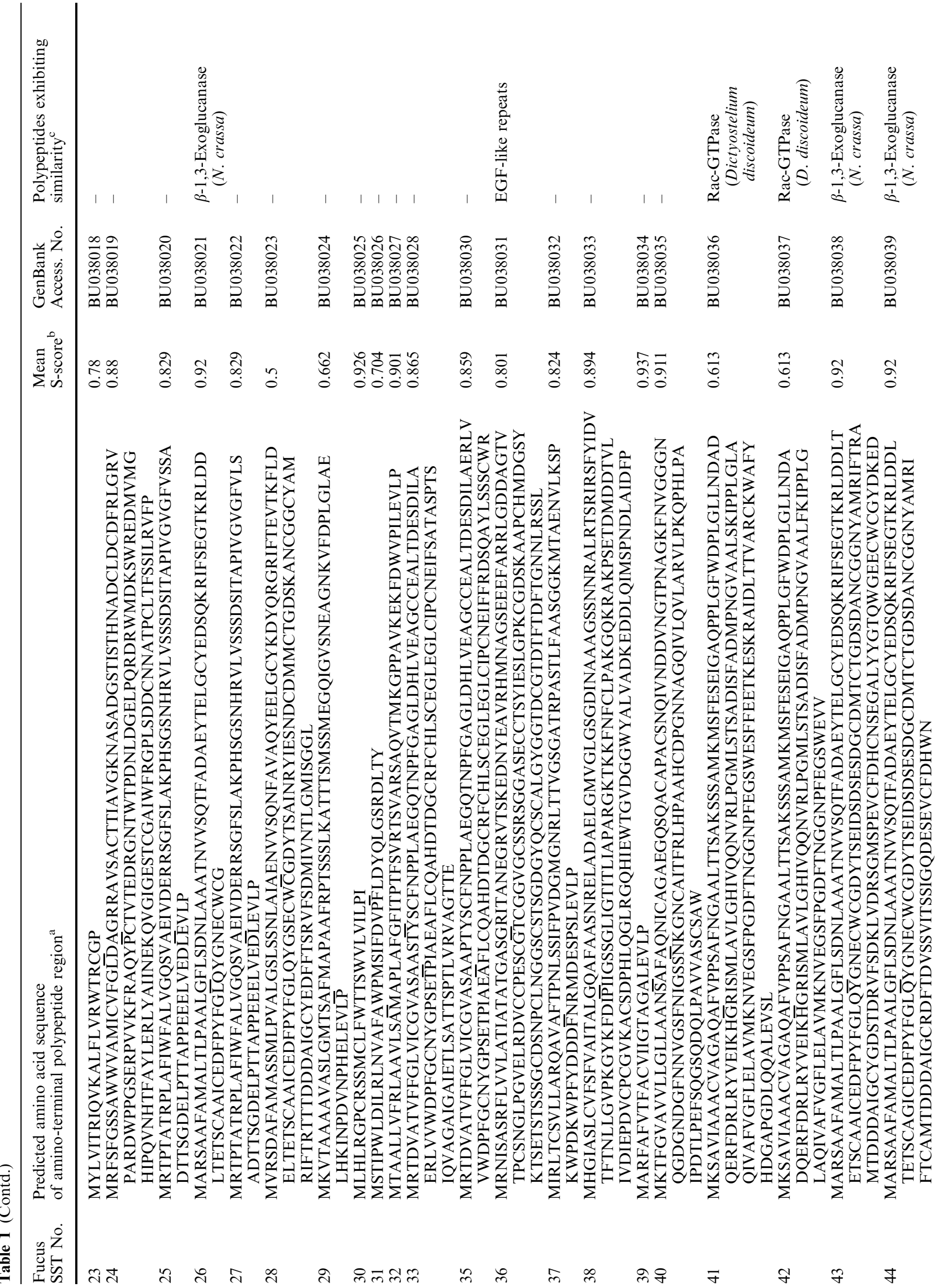




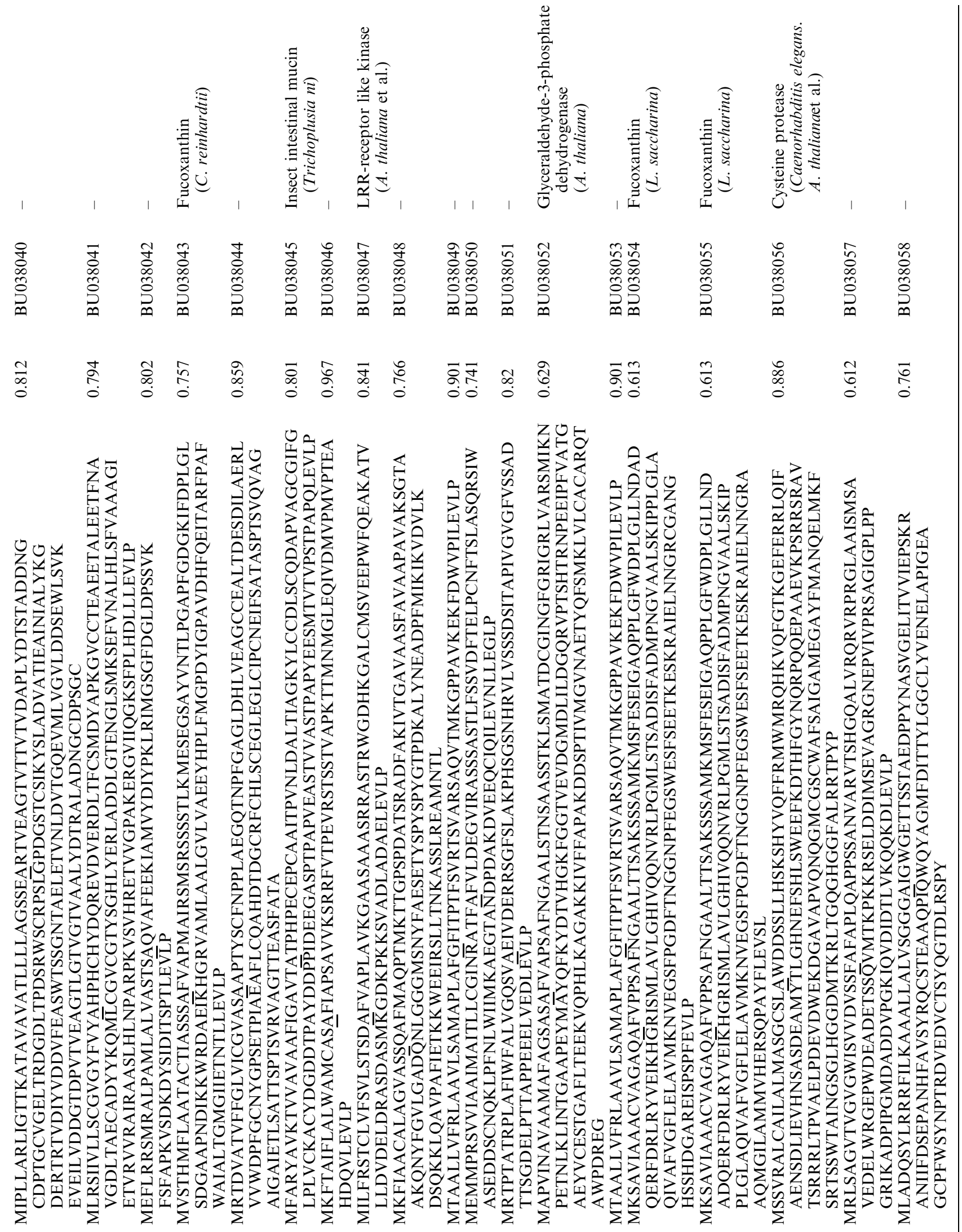

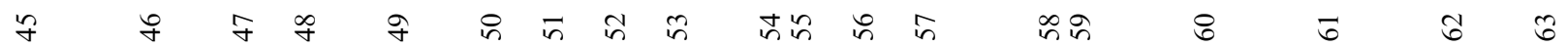




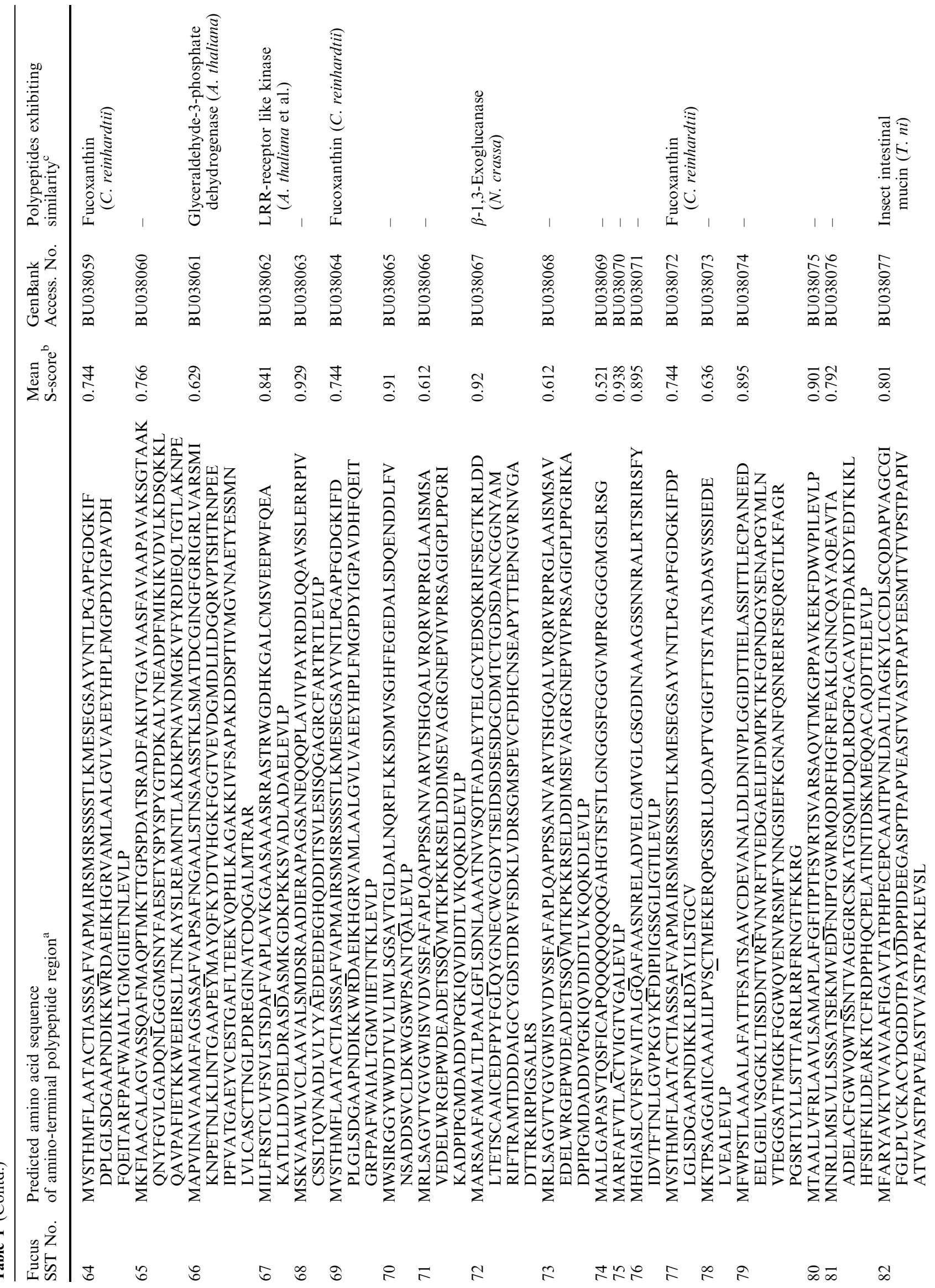




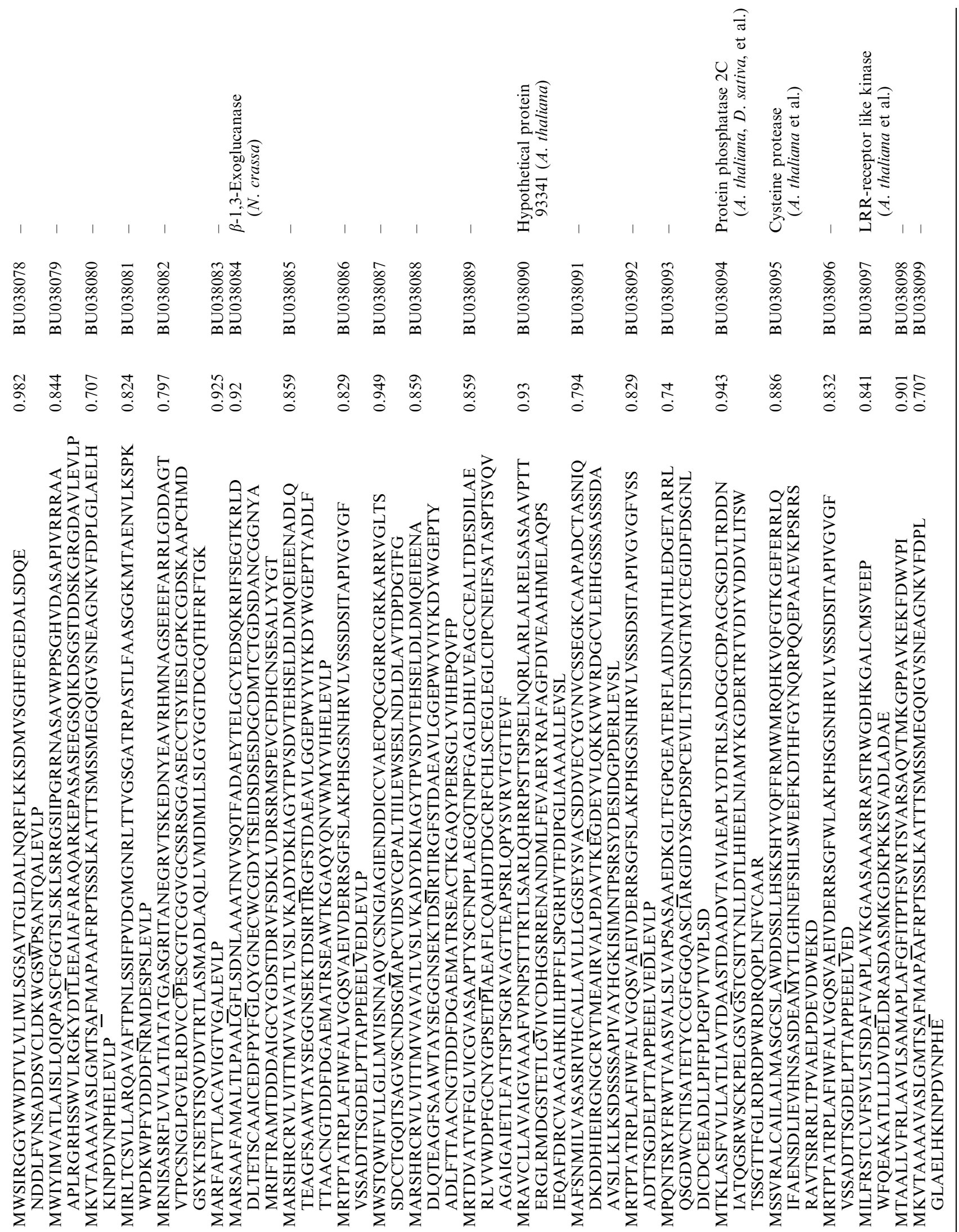

ஸ 


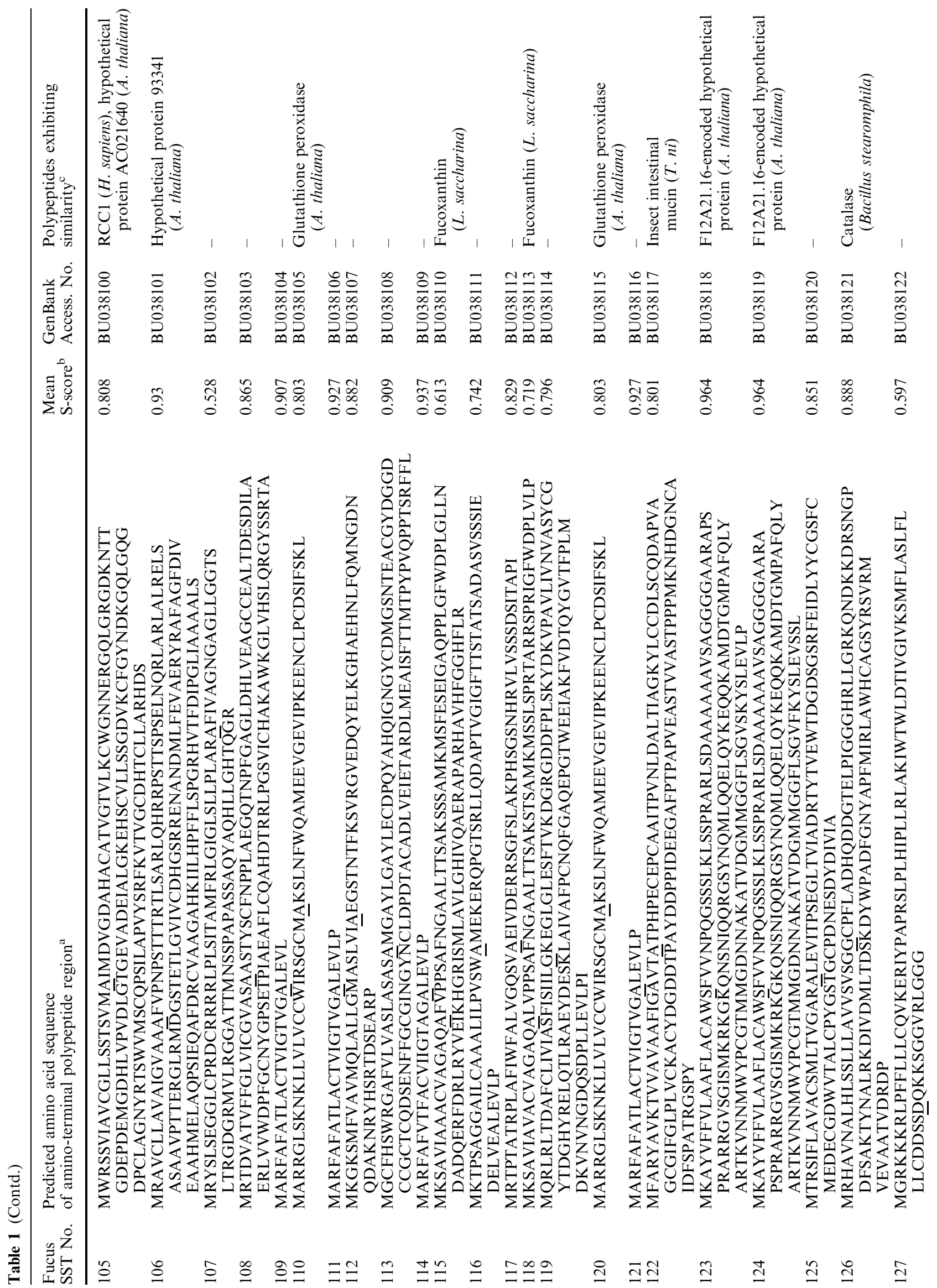


苞

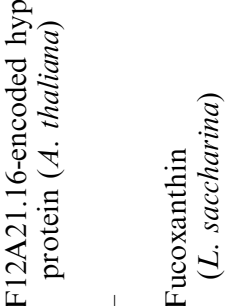

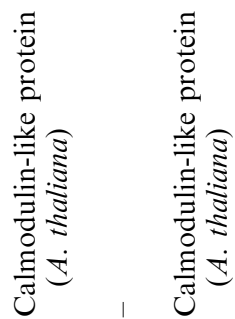

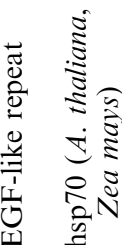

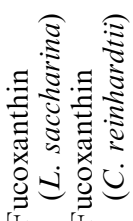

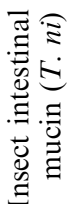

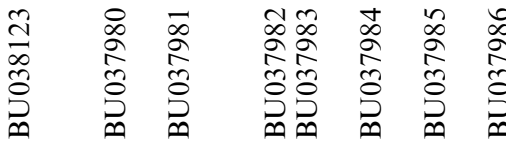

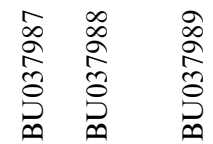

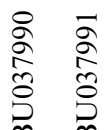

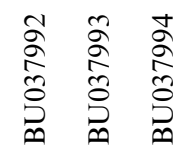

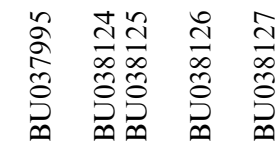

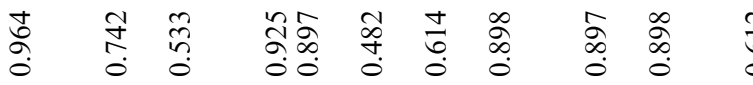

?̊.

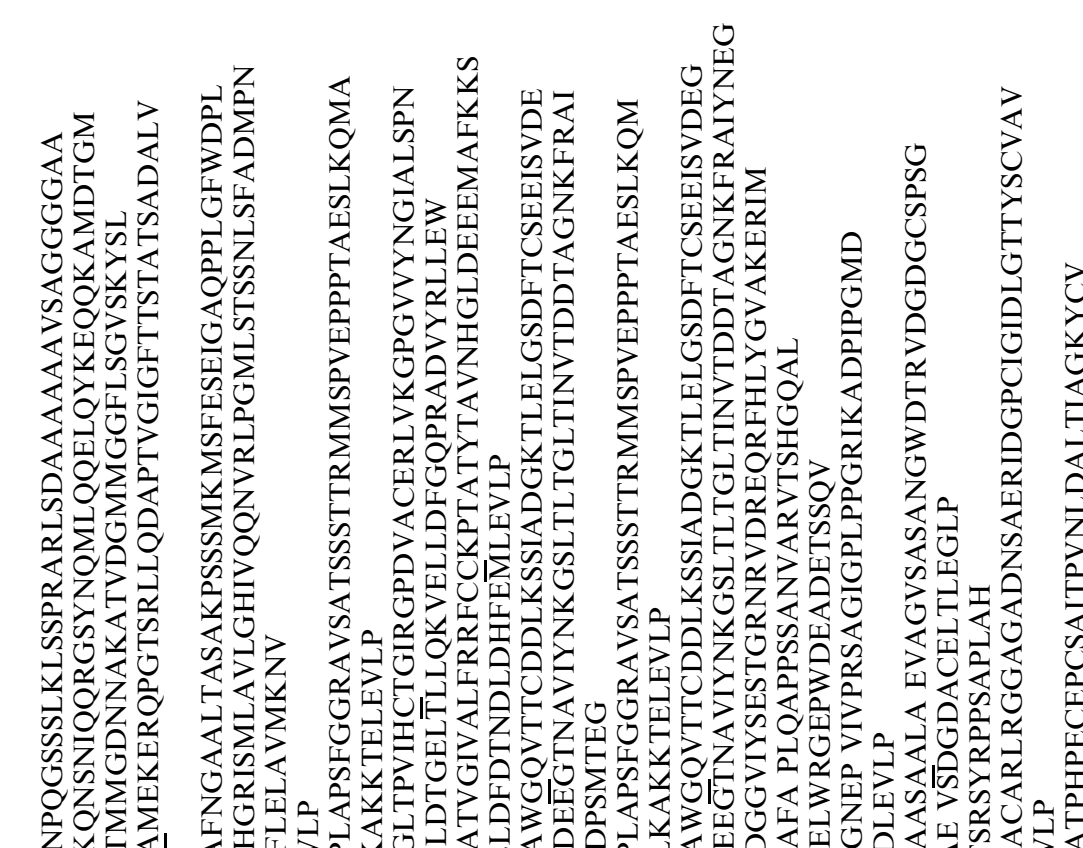

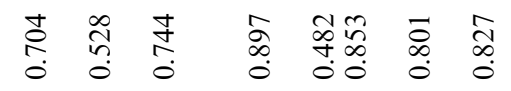

恣

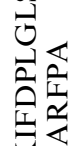

竞

步塄文

空重

政文

它怘

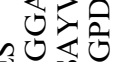

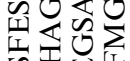

可胫㝴

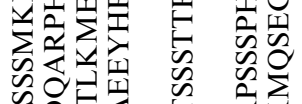

至氛交

运牙苟

事被

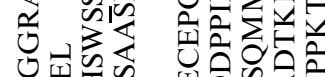

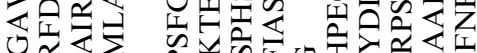

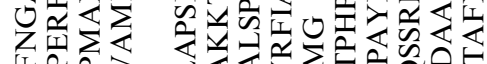

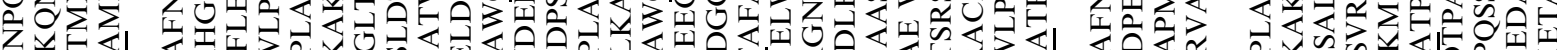

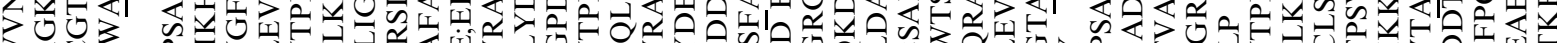

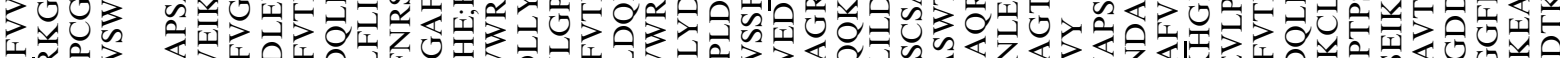

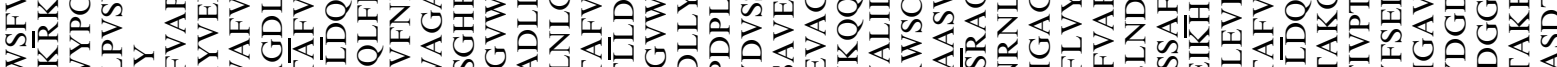

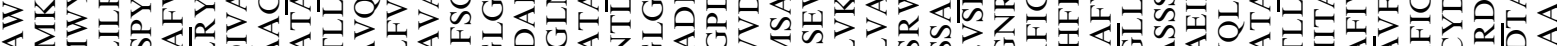

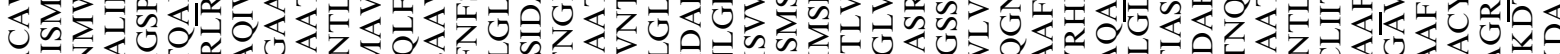

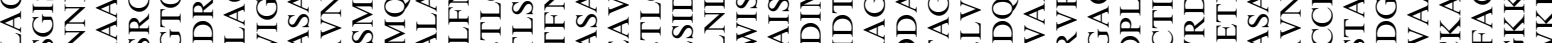

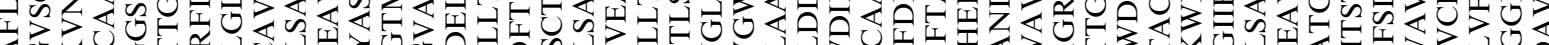

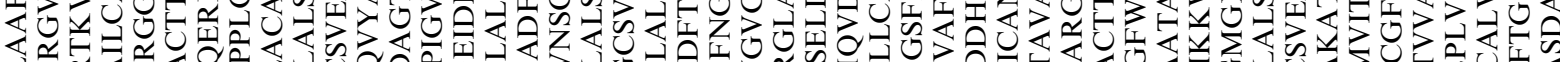

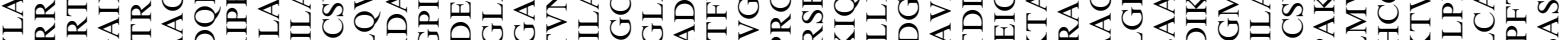

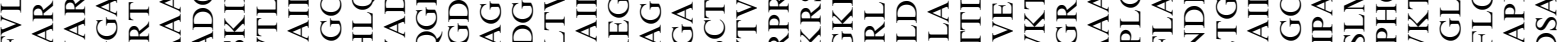

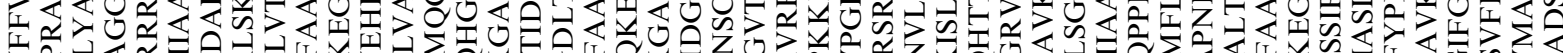

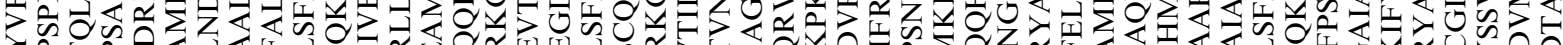

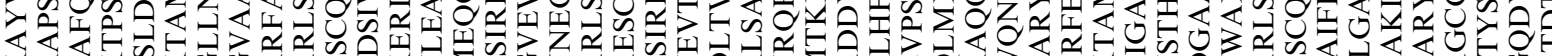

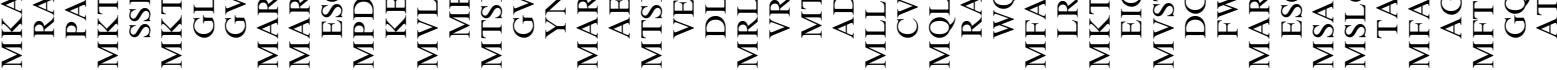

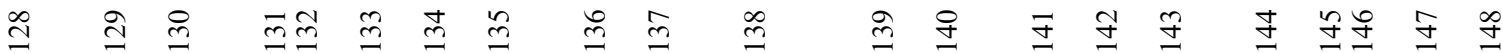




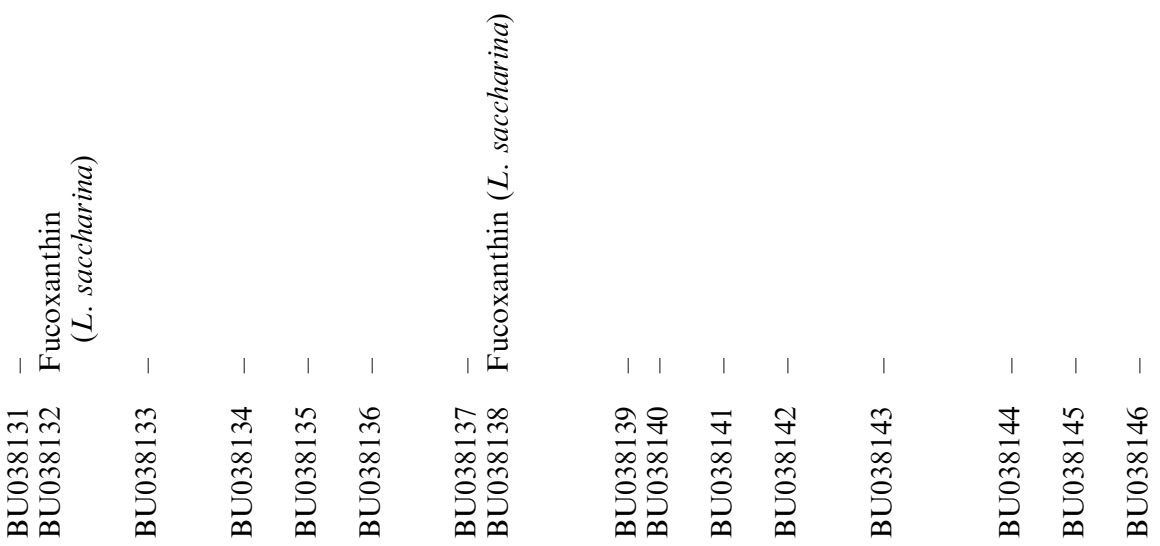

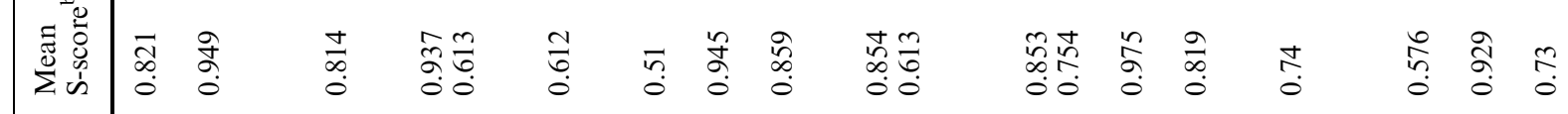

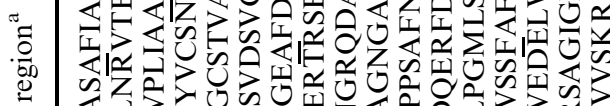

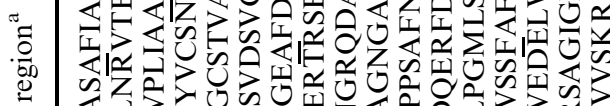

3
2
21
2

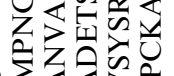

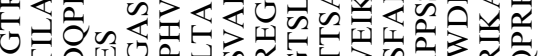

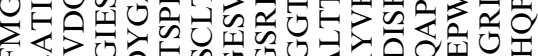

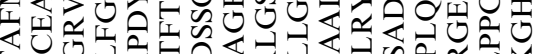

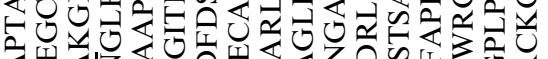

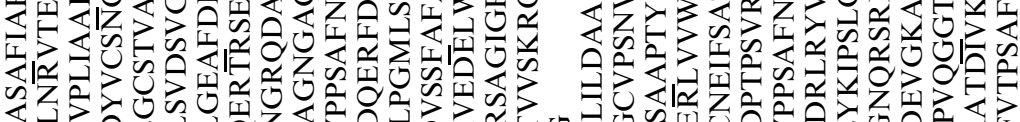

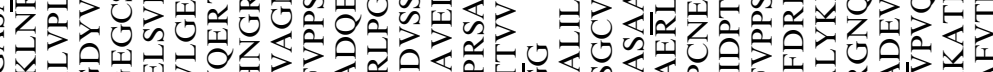

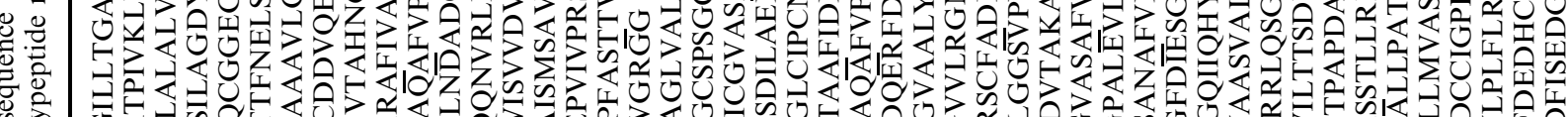

至

文

U

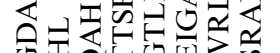

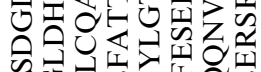

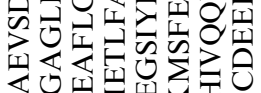

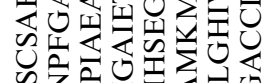

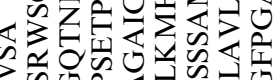

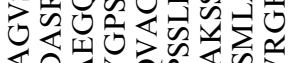

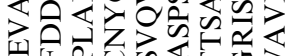

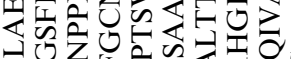

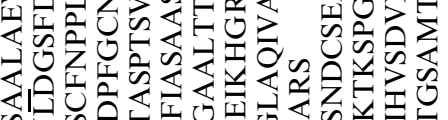

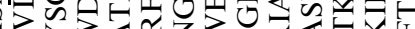

迳运焉

핀

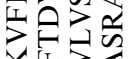

北文

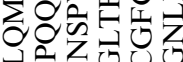

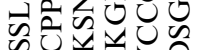

领尚尚它空

绕四四

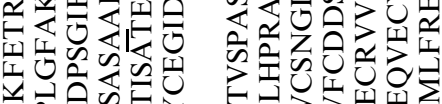

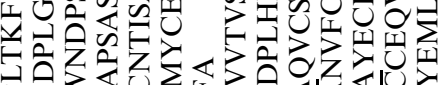

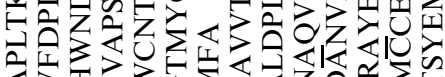

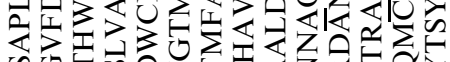

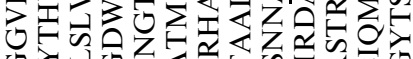

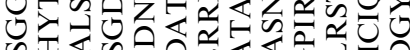

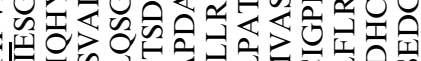

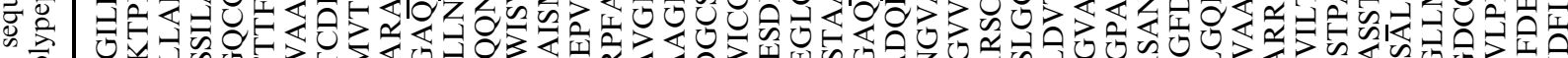

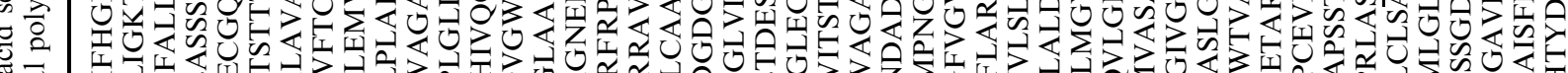

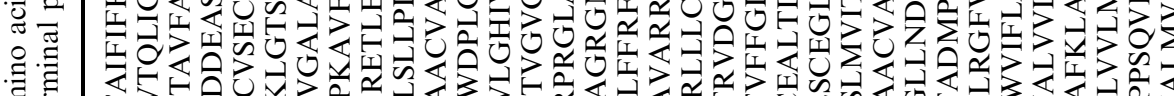

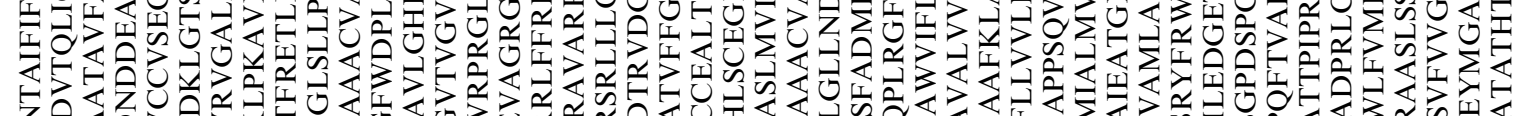

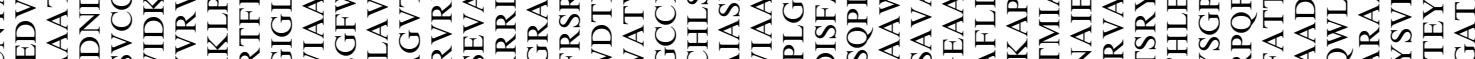

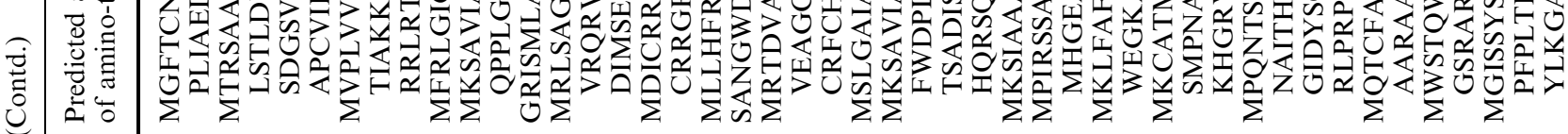

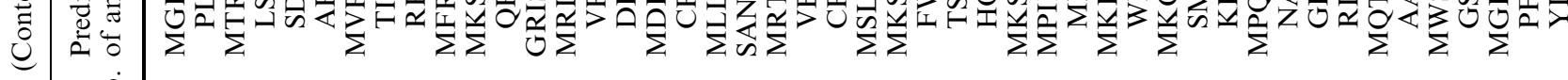

司

$\stackrel{0}{Z}$

守

$\bar{n}$

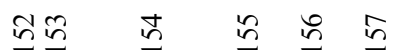

in

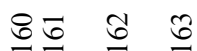

ț

$\ddot{6}$ 
Eighteen plasmids representing three different sequences encode polypeptides exhibiting strong similarity to the fucoxanthins, chlorophyll $a / b$-binding proteins that function in harvesting light for photosynthesis. Additional polypeptides isolated more than once exhibit similarity to previously characterized proteins, including glyceraldehyde-3-phosphate dehydrogenase, a cysteine protease, mucins, and several uncharacterized plant open reading frames (ORFs; Table 3). A number of sequences with similarity to known proteins were identified in the screen only a single time, including polypeptides similar to cell-surface and intracellular signaling proteins such as FK506binding protein (FKBP), mitogen-activated protein (MAP) kinase, and pp2C subunits.

\section{Discussion}

Secreted polypeptides provide potential links between the intracellular and extracellular environments of cells, often functioning both to provide communication across the plasma membrane and to maintain a physical link that mediates cell/extracellular matrix (ECM) interactions. Klein et al. (1996) and Jacobs et al. (1997) independently developed assays that use Saccharomyces cerevisiae to screen large numbers of mammalian sequences for those that encode a functional signal peptide. This method has also recently been used to identify novel signal peptides in plants (Goo et al. 1999). As expected, the proteins identified in these screens included transmembrane receptors, extracellular matrix proteins, and cell adhesion molecules, as well as ion channels, cytokines, chemokines, and proteins of the endomembrane system (Klein et al. 1996; Jacobs et al. 1997; Goo et al. 1999).

We are interested in understanding the mechanism by which zygotes of the fucoid algae develop from symmetric, apolar eggs to molecularly and morphologically asymmetric embryos. This asymmetric development involves both the generation of a polar axis within the fertilized egg and the subsequent asymmetric growth that produces the morphologically distinct rhizoid and thallus ends of the embryo. It is likely that the reception and signaling of environmental cues influencing polarity, selection and fixation of a polar axis, and subsequent asymmetric cell growth are dependent, at least in part, on polypeptides expressed at the cell surface or in the extracellular matrix. In an effort to identify proteins potentially involved in these processes, we have used the SST screen to identify polypeptides expressed in Fucus distichus zygotes that can function as signal peptides.

We isolated 222 plasmids containing Fucus cDNA sequences. Assuming that the open reading frame that encodes a signal peptide is in-frame with invertase in those plasmids that contain multiple reading frames, $76.1 \%(169 / 222)$ of the isolated plasmids were predicted by the SignalP signal peptide prediction program 
(Nielsen et al. 1997) to encode a signal peptide. This percentage is comparable to the $85 \%$ reported for mammalian sequences (Klein et al. 1996; Jacobs et al. 1997) and the $76 \%$ reported for Arabidopsis (Goo et al. 1999). A possible explanation for the lower percentage of peptide-containing polypeptides isolated in our screen and the Arabidopsis screen is the inherent difficulty of predicting degenerate sequences such as signal peptides. The SignalP algorithm is based on the polypeptide sequence of proteins containing known signal peptides that had previously been entered in GenBank (Nielsen et al. 1997). Because of this, the algorithm is more accurate in predicting signal peptides exhibiting some similarity to those sequences utilized in generating the algorithm (Nielsen et al. 1997). Very few secreted proteins have been identified from Fucus distichus or other brown algae, and thus these sequences could not comprise a major portion of the SignalP data set. As a result, sequences derived from brown algae are less likely to be predicted correctly by the SignalP program. In addition, Kaiser et al. (1987) observed that roughly $20 \%$ of randomly assembled polypeptides could function as signal sequences using a similar yeast invertase assay. It is possible that Fucus expresses a high number of polypeptides that do not have a prototypical signal peptide but do retain a minimal level of "secretory activity," and thus are detected as false positives in the SST screen. Interestingly, most of the false positive sequences isolated in the Arabidopsis SST screen were rRNAs (Goo et al. 1999), suggesting that very short hydrophobic sequences may be able to function as signal peptides in this screen. In any case, the presence of a predicted signal peptide in more than $76 \%$ of cDNAs isolated in our screen indicates that we have most likely significantly enriched for signal peptide-containing genes expressed during asymmetric cell growth in Fucus.

Comparison of the predicted Fucus polypeptides against GenBank using BlastP (Altschul et al. 1990) revealed significant sequence similarity between some Fucus polypeptides and proteins found in other organisms. Several of these polypeptides, including EGF-like repeat-containing proteins, LRR-receptor kinases, and $\beta$-1,3-exoglucanases, perform important functions in asymmetric cell growth and development in other multicellular organisms.

Epidermal growth factor (EGF)-like repeats are cysteine-rich polypeptide domains found in a diverse array of proteins. Although the EGF-like repeat motif was first identified in EGF, a potent soluble peptide stimulator of cell division, other proteins containing these repeat sequences perform a broad range of primarily extracellular functions. These proteins include growth factors, transmembrane receptors, adhesion molecules, soluble and transmembrane ligands, and extracellular matrix proteins (reviewed in Bork et al. 1996, Singson et al. 1998). In metazoans, EGF repeat-containing proteins are involved in cell-cell adhesion, cell and tissue polarity, sperm/egg fusion, asymmetric neuron growth, leg development, metamorphosis, and other functions (Rao et al. 1995). In plants, the wall-associated kinase (WAK) family of transmembrane receptors also contain EGFlike repeats and thus far have been shown to be involved in cell elongation, seedling shoot and root development, and pathogen response (He et al. 1998, 1999; Lally et al. 2001). We have isolated three different Fucus cDNA clones encoding polypeptides containing at least one EGF-like repeat. These predicted polypeptides contain cysteine-rich regions with significant similarity to EGFlike repeat consensus sequences and even higher similarity to specific EGF repeat-containing proteins, including the FAT protocadherin, Notch transmembrane receptors, Caspr proteins (see Fig. 3). All three of these protein types are localized asymmetrically in metazoan cells and have been proposed to have roles in polarized cell organization and asymmetric growth, and exhibit similarity to proteins that organize localized multiprotein complexes and mediate linkage between the cytoskeleton and ECM (Peles and Salzer 2000; Gollan et al. 2002; Strutt et al. 2002). Fucus embryos undergoing asymmetric growth require an intact, polarized microfilament network, localized secretion, and an extracellular matrix component in order to maintain oriented expansion at the rhizoid tip (Quatrano 1997). These requirements have led several groups to propose the presence of a protein complex at the site of tip growth that links the actin cytoskeleton and ECM (Quatrano and Shaw 1997; Brownlee and Bouget 1998). Central to this complex is a transmembrane protein (or proteins) that provides an essential link between microfilaments and the ECM, either by physical association, transmembrane signaling, or both. However, such a protein remains to be identified in Fucus. The similarity of the novel Fucus polypeptides described here to proteins that provide a transmembrane link that assists in defining cell polarity in metazoans may provide clues toward understanding the generation of asymmetry in fucoid embryos.

This screen also resulted in the isolation of three Fucus cDNAs (FucusSST052, 067, and 102) that encode secreted polypeptides with a similarity to a 29 -aminoacid region of plant leucine-rich repeat receptor kinases. The leucine-rich repeat has been identified in proteins in metazoans, algae, and plants. In higher plants, LRR receptor kinases form a large family of transmembrane receptors (Torii 2000; Shiu and Bleecker 2001), members of which contribute to plant defense, regulate development, and mediate hormone detection (Torii 2000; Li et al. 2002; Nam and Li 2002). The LRR-receptor kinases thus far identified interact extracellularly with steroid or peptide ligands and function as heterodimers or tetramers to transmit their signal intracellularly through Ser/ Thr kinase activity (Li and Chory 1997; Jinn et al. 2000; Trotochaud et al. 2000; Li et al. 2002; Nam and Li 2002). In addition to an $\mathrm{N}$-terminal signal peptide, these receptors are comprised of a variable number of extracellular LRR repeats, a single transmembrane domain, and, in most cases, an intracellular Ser/Thr kinase domain (Shiu and Bleecker 2001). The Fucus cDNA 


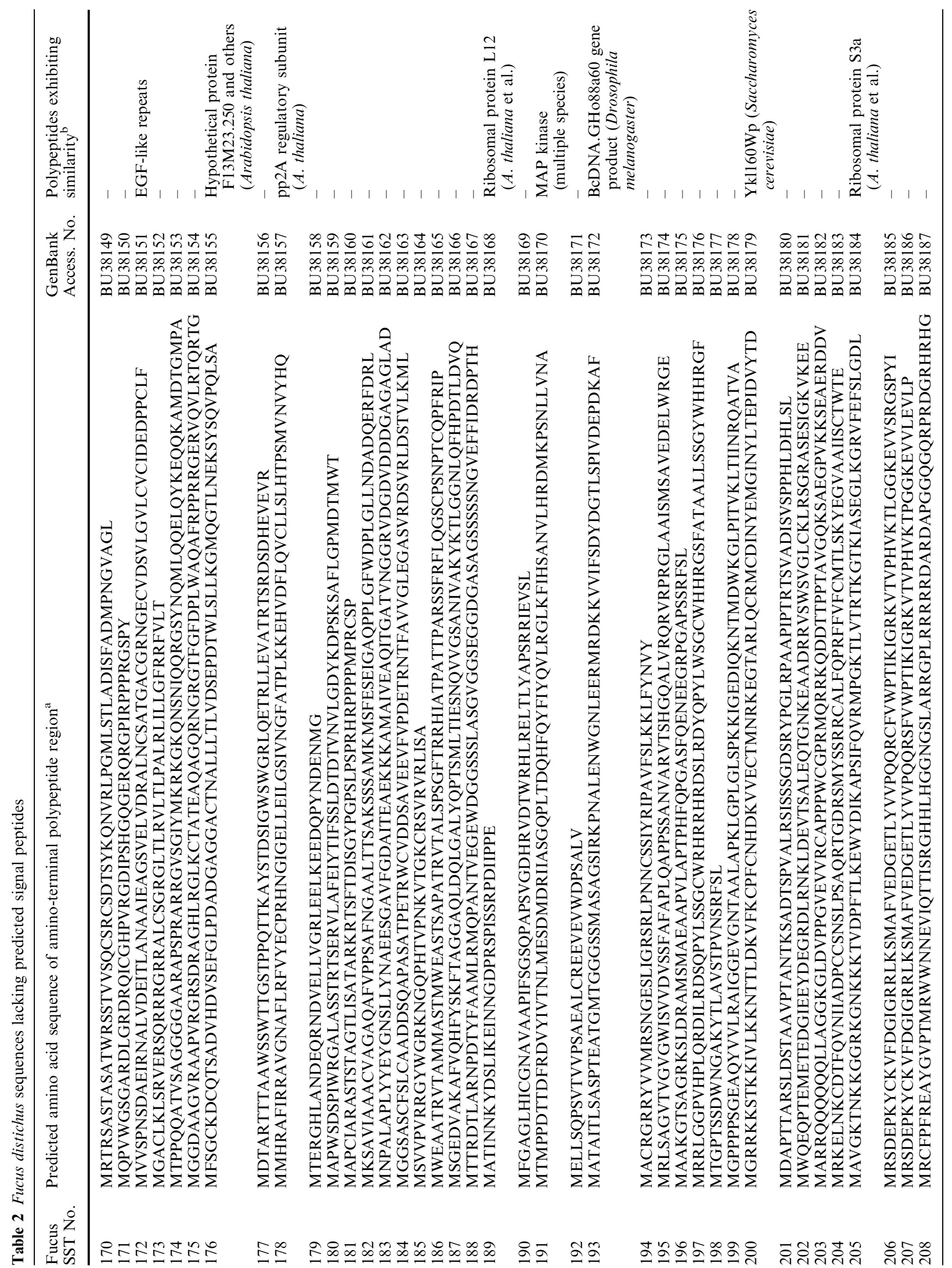




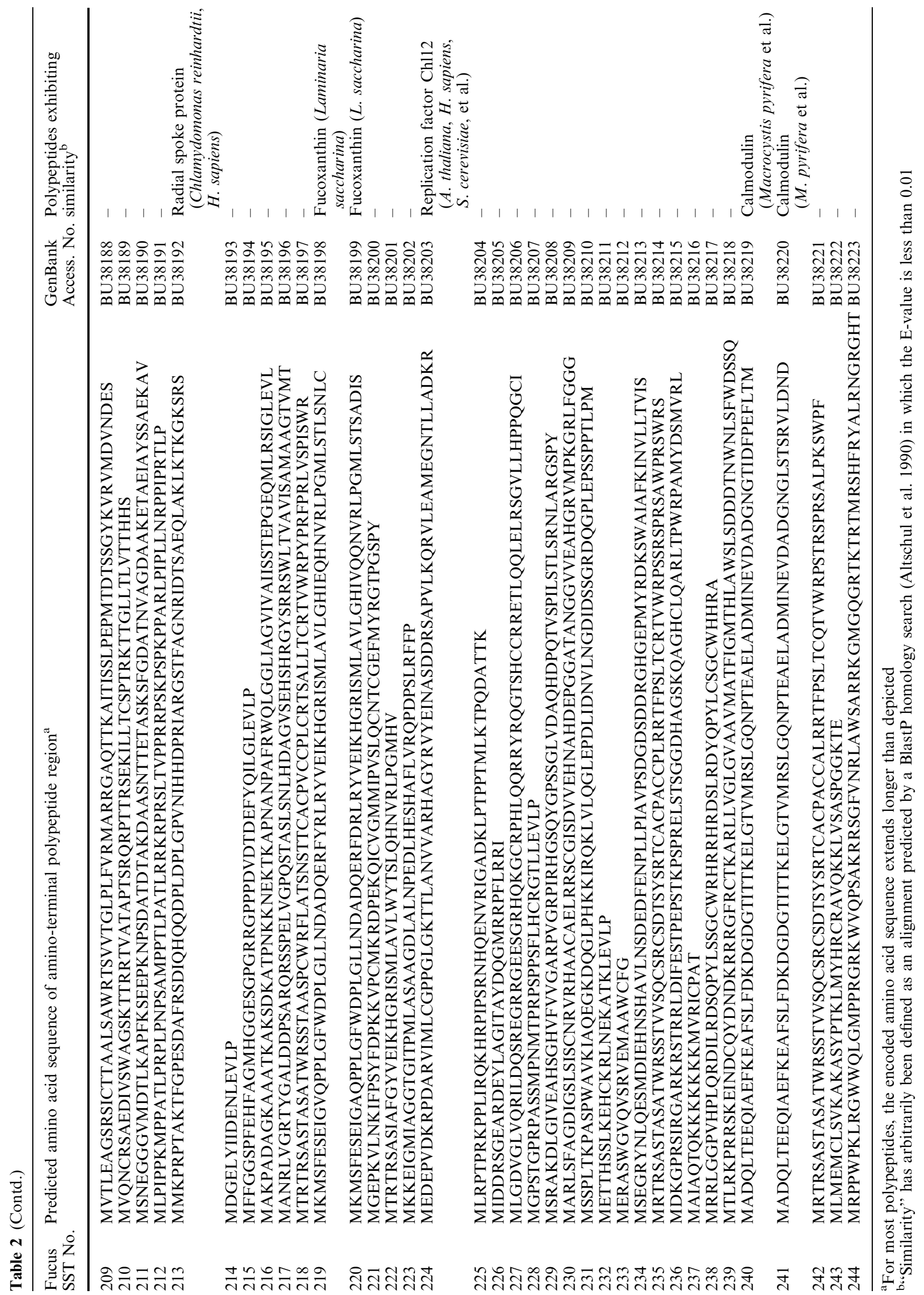


Table 3 Fucus distichus polypeptide sequences isolated multiple times from signal peptide screen

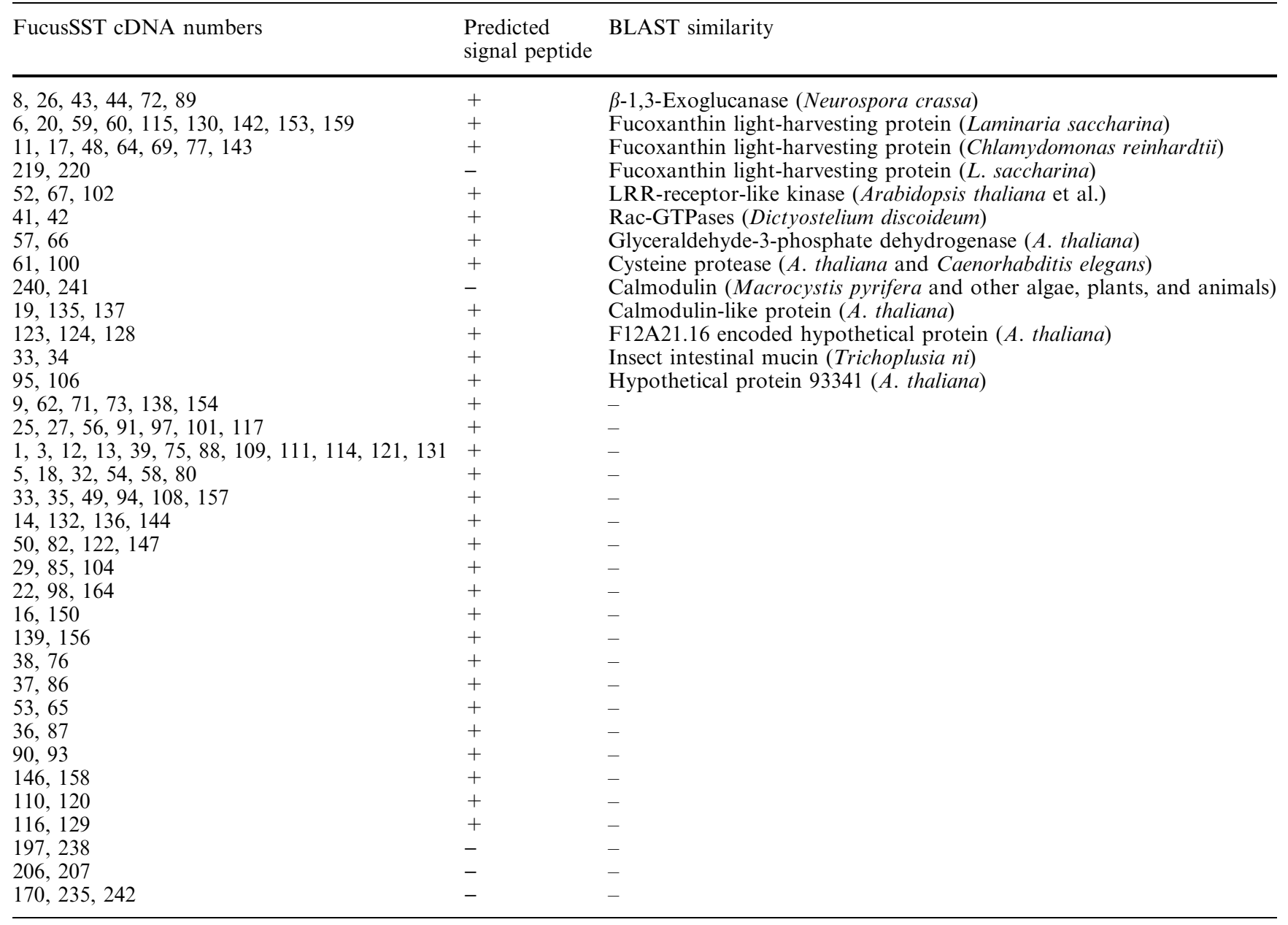

sequence we have identified as having similarity with several plant LRR-receptor kinases encodes only the Nterminal 101 amino acids of the Fucus protein, including an amino-terminal signal peptide followed by a leucinerich domain. Interestingly, this leucine-rich domain does not conform to the LRR consensus sequence. Instead, it exhibits greatest similarity to a leucine-containing region found near the C-terminus of a highly similar group of LRR-receptor kinases identified by genetic analysis and genomic sequencing projects ( $\mathrm{Li}$ and Wurtzel 1998). The function of this domain in our Fucus clones and in the related plant sequences remains to be determined.

Six essentially identical Fucus polypeptides that are predicted to contain signal peptides also exhibit similarity to $\beta$-1, 3-exoglucanase from Neurospora crassa and other fungi (Fig. 3). Glucanase proteins from vascular plants are secreted through the ER to Golgi pathway (Pihakaski-Maunsbach et al. 1996). $\beta-1,3-$ Glucanase expression appears to play a role in plant embryogenesis and germination (Simmons 1994; Cheong et al. 2000; Helleboid et al. 2000), in addition to functioning in plant defense, tissue differentiation, and senescence (reviewed in Simmons 1994). In yeast, regulated $\beta$-glucan synthesis at the bud tip is essential for cell wall expansion during polar growth (Drgonova et al. 1996; Qadota et al 1996). Whether the regulation of $\beta$ glucan synthesis and degradation plays a role in asymmetric growth in fucoid zygotes remains to be clarified. Hable and Kropf (1998) have observed that the cell wall of fucoid algae weakens detectably at the site of presumptive rhizoid outgrowth. Exoglucanase activity may be responsible for partial breakdown of extracellular carbohydrates prior to asymmetric growth, allowing for cell surface expansion at a site of weakened cell wall integrity. However, the role of $\beta$-1,3-exoglucanase in this expansion is unclear, as $\beta$-1,4-exoglucanase is the primary exoglucanase activity reported in fucoid embryos (Stevens and Quatrano 1978). The isolation and characterization of the $\beta$-1,3-exoglucanase we have identified will further clarify the role of this polypeptide in cell wall organization and asymmetric cell growth.

Several other signal peptide-containing proteins from Fucus were identified one or more times in our screen, including putative cysteine proteases, BiP and Hsp70 chaperones, mucins, and polypeptides with similarity to hypothetical proteins identified in large-scale sequencing projects (see Table 1). Fucoxanthin proteins involved in light harvesting were also isolated multiple times, 


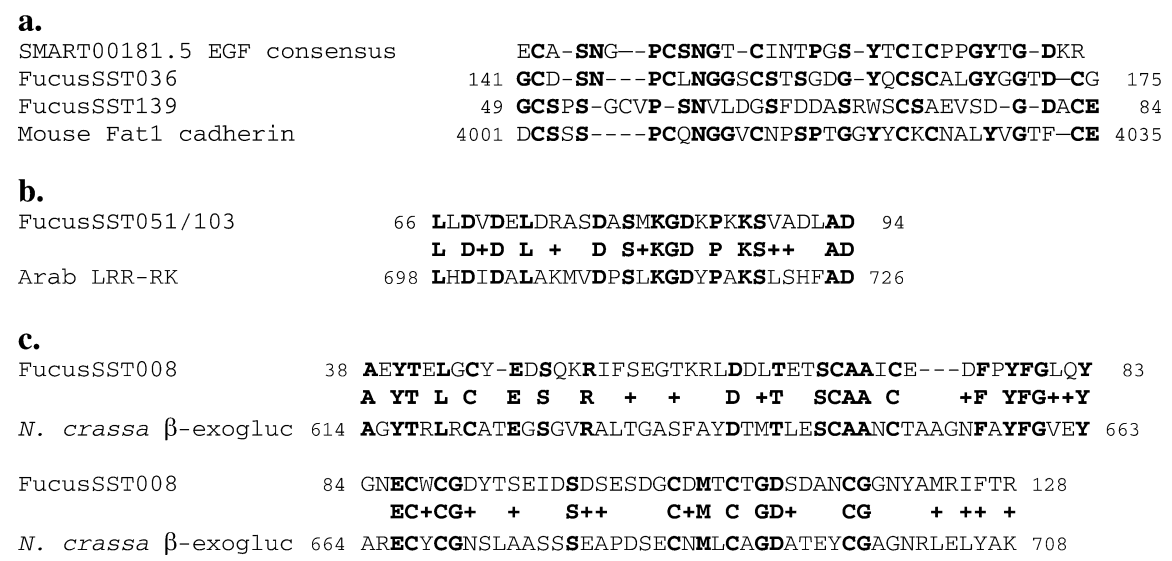

b.

FucusSST051/103

66 LLDVDELDRASDASMKGDKPKKSVADLAD 94

L D+D L + D S+KGD P KS++ AD

Arab LRR-RK

698 LHDIDALAKMVDPSLKGDYPAKSLSHFAD 726

c.

FucusSTT008 38 AEYTELGCY-EDSQKRIFSEGTKRLDDLTETSCAAICE---DFPYFGLQY 83

N. crassa $\beta$-exogluc 614 AGYTRLRCATEGSGVRALTGASFAYDTMTLESCAANCTAAGNFAYFGVEY 663

FucusSST008 84 GNECWCGDYTSEIDSDSESDGCDMTCTGDSDANCGGNYAMRIFTR 128

$\mathrm{EC}+\mathrm{CG}++\mathrm{S}++\quad \mathrm{C}+\mathrm{M}$ C GD+ CG ++++

N. crassa $\beta$-exogluc 664 ARECYCGNSLAASSSEAPDSECNMLCAGDATEYCGAGNRLELYAK 708

Fig. 3a-c Secreted polypeptides expressed in Fucus embryos exhibit similarity to protein types important for polar growth. a Epidermal growth factor (EGF)-like regions are found in secreted Fucus polypeptides. The consensus sequence of the SMART00181.5 EGF-like domain was aligned with Fucus predicted polypeptides FucusSST036 and 139. Also included for comparison is an EGF-like region from the mouse protocadherin Fat1. Regions of identity between at least two of the four sequences are indicated in bold. b Secreted Fucus polypeptides contain similarity to leucine-rich repeat (LRR) receptor protein kinases. A 29-amino-acid region from Fucus secreted peptides \#51 and 103 was aligned with a region of an Arabidopsis open reading frame encoding a putative LRR-receptor protein kinase (GenBank accession number 18399502). c Alignment of a region of FucusSST008 with a Neurospora crassa $\beta$-1,3-exoglucanase (GenBank CAC18170). Alignments were performed using BlastP (Altschul et al 1990). Bold letters indicate the presence of identical residues, while $(+)$ highlights the location of residues with similar features

potentially due to the similarity between chloroplast targeting sequences and signal peptides (Emanuelsson et al. 1999). Interestingly, analysis of these Fucus fucoxanthin sequences by TargetP indicates that the polypeptides can potentially function as chloroplast targeting sequences, but more closely resemble signal peptides (data not shown). Finally, polypeptides lacking a predicted signal sequence include sequences similar to calmodulin, calmodulin-like proteins, a MAP kinase, FK506 binding protein, pp2C phosphatase, pp2A regulatory subunit, and $S$. cerevisiae Ykl160Wp, among others (see Table 2). Interestingly, the vast majority of polypeptides isolated from the screen contain only very limited similarity or lack any predicted similarity to previously identified proteins. This result may be expected, given the small number of algal sequences in GenBank and the distant evolutionary relationship between fucoid algae and organisms in which the most extensive sequencing work has been completed.

Secreted molecules are critical for the generation of polarity and subsequent asymmetric cell growth in fucoid zygotes. However, the exact molecules necessary for these molecular events remain to be identified. The identification of secreted Fucus polypeptides with similarity to plant and metazoan proteins mediating asymmetric cell growth provides an important step in determining the proteins important for the establishment and maintenance of asymmetry. The fucoid algae have long provided a model system for studying the development of polarity because large numbers of free-living, synchronously developing embryos can be obtained and because the polar axis of the embryo population can be environmentally induced and altered during early development (Kropf 1997; Brownlee and Bouget 1998). The ability to perform microinjections of nucleic acids and proteins into living Fucus zygotes also makes antibody inhibition, green fluorescent protein (GFP) localization, and RNAi inhibition studies possible avenues for future investigation. The isolation of full-length clones of the gene fragments isolated in this screen will allow for functional analysis of each polypeptide and will shed light on the role of these cell surface proteins in asymmetric cell growth in multicellular organisms.

Acknowledgements We thank Crispin Taylor (University of North Carolina, Chapel Hill, NC, USA) for constructing the original Fucus $\lambda$ cDNA library, John Fowler (Oregon State University, Corvallis, OR, USA) and Punita Nagpal (University of North Carolina, Chapel Hill, NC, USA) for helpful advice and insightful discussions, Bruce Kohorn and Zheng-Hui He (Duke University, Durham, NC, USA) for WAK2 plasmids, Richard Meagher (University of Georgia, Athens, GA, USA) for actin sequences, and the Genetics Institute (Boston, MA, USA) for the SST plasmid. This work was supported by NIH fellowship GM-18400-02 to K.D.B. and NSF grant IBN 96-04672 to R.S.Q.

\section{References}

Altschul SF, Gish W, Miller W, Myers EW, Lipman DJ (1990) Basic local alignment search tool. J Mol Biol. 215:403-410

An YQ, McDowell JM, Huang S, McKinney EC, Chambliss S, Meagher RB (1996) Strong, constitutive expression of the Arabidopsis ACT2/ACT8 actin subclass in vegetative tissues. Plant J 10:107-121

Appel RD, Bairoch A, Hochstrasser DF (1994) A new generation of information retrieval tools for biologists: the example of the ExPASy WWW server. Trends Biochem.Sci 19:258-260

Apt KE, Clendennen SK, Powers DA, Grossman AR (1995) The gene family encoding the fucoxanthin chlorophyll proteins from the brown alga Macrocystis pyrifera. Mol Gen Genet 246:455464

Ausubel FM, Brent R, Kingston RE, Moore DD, Seidman JG, Smith JA, Struhl KJ (eds) (1995) Current protocols in molecular biology. Wiley, New York, chpt 13 
Belanger KD, Quatrano RS (2000a) Polarity: the role of localized secretion. Curr Opin Plant Biol 3:67-72

Belanger KD, Quatrano RS (2000b) Membrane recycling occurs during asymmetric tip growth and cell plate formation in Fucus distichus zygotes. Protoplasma 212:24-37

Bork P, Downing AK, Kieffer B, Campbell ID (1996) Structure and distribution of modules in extracellular proteins. Q Rev Biophys 29:119-167

Brawley SH, Quatrano RS (1979) Sulfation of fucoidin in Fucus embryos. 4. Autoradiographic investigations of fucoidin sulfation and secretion during differentiation and the effects of cytochalasin treatment. Dev Biol 73:193-205

Brownlee C, Bouget FY (1998) Polarity determination in Fucus: from zygote to multicellular embryo. Semin Cell Dev Biol 9:179-185

Brownlee C, Bouget F-Y, Corellou F (2001) Choosing sides: establishment of polarity in zygotes of fucoid algae. Semin Cell Dev Biol 12:345-351

Cheong YH, Kim CY, Chun HJ, Moon BC, Park HC, Kim JK, Lee SH, Han CD, Lee SY, Cho MJ (2000) Molecular cloning of a soybean class III beta-1,3-glucanase gene that is regulated both developmentally and in response to pathogen infection. Plant Sci 154:71-81

Cove DJ (2000) The generation and modification of cell polarity. J Exp Bot 51:831-838

Doe CQ, Bowerman B (2001) Asymmetric cell division: fly neuroblast meets worm zygote. Curr Opin Cell Biol 13:68-75

Drgonova J, Drgon T, Tanaka K, Kollar R, Chen GC, Ford RA, Chan CS, Takai Y, Cabib E (1996) Rholp, a yeast protein at the interface between cell polarization and morphogenesis. Science 272:277-279

Drubin DG, Nelson WJ (1996) Origins of cell polarity. Cell 84:335344

Emanuelsson O, Nielsen H, von Heijne G (1999) ChloroP, a neural network-based method for predicting chloroplast transit peptides and their cleavage sites. Protein Sci 8:978-984

Gollan L, Sabanay H, Poliak S, Berglund EO, Ranscht B, Peles E (2002) Retention of a cell adhesion complex at the paranodal junction requires the cytoplasmic region of Caspr. J Cell Biol 157:1247-1256

Goo JH, Park AR, Park WJ, Park OK (1999) Selection of Arabidopsis genes encoding secreted and plasma membrane proteins. Plant Mol Biol 41:415-423

Grebe M, Xu J, Scheres B (2001) Cell axiality and polarity in plants-adding pieces to the puzzle. Curr Opin Plant Biol 4:520-526

Hable WE, Kropf DL (1998) Roles of secretion and the cytoskeleton in cell adhesion and polarity establishment in Pelvetia compressa zygotes. Dev Biol 198:45-56

Hable WE, Kropf DL (2000) Sperm entry induces polarity in fucoid zygotes. Development 127:493-501

He Z-H, He D, Kohorn BD (1998) Requirement for the induced expression of a cell wall associated receptor kinase for survival during the pathogen response. Plant J 14:55-63

He Z-H, Cheeseman I, He D, Kohorn BD (1999) A cluster of five cell wall-associated receptor kinase genes, Wak1-5, are expressed in specific organs of Arabidopsis. Plant Mol Biol 39:1189-1196

Helleboid S, Chapman A, Hendriks T, Inze D, Vasseur J, Hilbert JL (2000) Cloning of beta-1,3-glucanases expressed during Cichorium somatic embryogenesis. Plant Mol Biol 42:377-386

Ito H, Fukuda Y, Murata K, Kimura A (1983) Transformation of intact yeast cells treated with alkali cations. J Bacteriol 153:163168

Jacobs KA, Collins-Racie LA, Colbert M, Duckett M, GoldenFleet M, Kelleher K, Kriz R, LaVallie ER, Merberg D, Spaulding V, Stover J, Williamson MJ, McCoy JM (1997) A genetic selection for isolating cDNAs encoding secreted proteins. Gene 198:289-296

Jinn T, Stone J, Walker J (2000) HAESA, an Arabidopsis leucinerich repeat receptor kinase, controls floral organ abscission. Genes Dev 11:108-117
Johnson AE, van Waes MA (1999) The translocon: a dynamic gateway at the ER membrane. Annu Rev Cell Dev Biol 15:799842

Kaiser CA, Preuss D, Grisafi P, Botstein D (1987) Many random sequences functionally replace the secretion signal sequence of yeast invertase. Science 235:312-317

Klein RD, Gu Q, Goddard A, Rosenthal A (1996) Selection for genes encoding secreted proteins and receptors. Proc Natl Acad Sci USA 93:7108-7113

Kropf DL (1997) Induction of polarity in fucoid zygotes. Plant Cell 9:1011-1020

Lally D, Ingmire P, Tong H-Y, He Z-H (2001) Antisense expression of a cell wall-associated protein kinase, WAK4, inhibits cell elongation and alters morphology. Plant Cell 13:1317-1332

Li J, Chory J (1997) A putative leucine-rich repeat receptor kinase involved in brassinosteroid signal transduction. Cell 90:929-938

Li J, Wen J, Lease KA, Doke JT, Tax FE, Walker JC (2002) BAK1, an Arabidopsis LRR receptor-like protein kinase, interacts with BRI1 and modulates brassinosteroid signaling. Cell 110:213-222

Li Z, Wurtzel ET (1998) The ltk gene family encodes novel receptor-like kinases with temporal expression in developing maize endosperm. Plant Mol Biol 37:749-761

Martoglio B, Dobberstein B (1998) Signal sequences: more than just greasy peptides. Trends Cell Biol 8:410-415

Nakai K, Kanehisa M (1992) A knowledge base for predicting protein localization sites in eukaryotic cells. Genomics 14:897911

Nam KH, Li J (2002) BRI1/BAK1, a receptor kinase pair mediating brassinosteroid signaling. Cell 110:203-212

Ngsee JK, Hansen W, Walter P, Smith M (1989) Cassette mutagenic analysis of the yeast invertase signal peptide: effects on protein translocation. Mol Cell Biol 9:3400-3410

Nielsen H, Engelbrecht J, Brunak S, von Heijne G (1997) Identification of prokaryotic and eukaryotic signal peptides and prediction of their cleavage sites. Protein Eng 10:1-6

Novotny AM, Forman M (1974) The relationship between changes in cell wall composition and the establishment of polarity in Fucus embryos. Dev Biol 40:162-173

Peles E, Salzer JL (2000) Molecular domains of myelinated axons. Curr Opin Neurobiol 10:558-565

Pihakaski-Maunsbach K, Griffith M, Antikainen M, Maunsbach AB (1996) Immunogold localization of glucanase-like antifreeze protein in cold acclimated winter rye. Protoplasma 191:115-125

$\mathrm{Pu}$ R.S, Wozniak M, Robinson KR (2000) Cortical actin filaments form rapidly during photopolarization and are required for the development of calcium gradients in Pelvetia compressa zygotes. Dev Biol 222:440-449

Qadota H, Python CP, Inoue SB, Arisawa M, Anraku Y, Zheng Y, Watanabe T, Levin DE, Ohya Y (1996) Identification of yeast Rholp GTPase as a regulatory subunit of 1,3-beta-glucan synthase. Science 272:279-281

Quatrano RS (1982) Cell-wall formation in Fucus zygotes: a model system to study the assembly and localization of wall polymers. In: Brown RM (ed) Cellulose and other natural polymer systems. Plenum, London, pp 45-59

Quatrano RS (1997) Cortical asymmetries direct the establishment of cell polarity and the plane of cell division in the Fucus embryo. Cold Spring Harbor Symp Quant Biol 62:65-70

Quatrano RS, Crayton MA (1973) Sulfation of fucoidan in Fucus embryos I: possible role in localization. Dev Biol 30:29-35

Quatrano RS, Shaw S (1997) Role of the cell wall in the determination of cell polarity and the plane of cell division in Fucus embryos. Trends Plant Sci 2:15-21

Rao Z, Handford P, Mayhew M, Knott V, Brownlee GG, Stuart D (1995) The structure of a $\mathrm{Ca}^{2+}$-binding epidermal growth factor-like domain: its role in protein-protein interactions. Cell 82:131-141

Shaw SL, Quatrano RS (1996) Polar localization of a dihydropyridine receptor on living Fucus zygotes. J Cell Sci 109:335342 
Shiu SH, Bleecker AB (2001) Receptor-like kinases from Arabidopsis form a monophyletic gene family related to animal receptor kinases. Proc Natl Acad Sci USA 98:10763-10768

Simmons CR (1994) The physiology and molecular biology of plant 1,3- $\beta$-D-glucanases and 1,3;1,4- $\beta$-D-glucanases. Crit Rev Plant Sci 13:325-387

Singson A, Mercer KB, L'Hernault SW (1998) The C. elegans spe-9 gene encodes a sperm transmembrane protein that contains EGF-like repeats and is required for fertilization. Cell 93:71-79

Stevens PT, Quatrano RS (1978) Cell wall assembly in Fucus zygotes. II. Cellulose synthesis and deposition is controlled at the post-translational level. Dev Biol 62:518-525

Strutt D, Johnson R, Cooper K, Bray S (2002) Asymmetric localization of frizzled and the determination of notch-dependent cell fate in the Drosophila eye. Curr Biol 12:813-824
Torii KU (2000) Receptor kinase activation and signal transduction in plants: an emerging picture. Curr Opin Plant Biol 3:361367

Trotochaud AE, Jeong S, Clark SE (2000) CLAVATA3, a multimeric ligand for the CLAVATA1 receptor-kinase. Science 289:613-617

Vitale A, Denecke J (1999) The endoplasmic reticulum-gateway of the secretory pathway. Plant Cell 11:615-628

von Heijne G (1986) A new method for predicting signal sequence cleavage sites. Nucleic Acids Res. 14:4683-4690

Wagner VT, Brian L, Quatrano RS (1992) Role of vitronectin-like molecule in embryo adhesion of the brown alga Fucus. Proc Natl Acad Sci USA 89:3644-3648 